\title{
RESEARCH
}

Open Access

\section{CD300f immunoreceptor contributes to peripheral nerve regeneration by the modulation of macrophage inflammatory phenotype}

Hugo Peluffo ${ }^{1,2+}$, Patricia Solari-Saquieres ${ }^{1 \dagger}$, Maria Luciana Negro-Demontel ${ }^{1}$, Isaac Francos-Quijorna ${ }^{3}$, Xavier Navarro ${ }^{3}$, Ruben López-Vales ${ }^{3}$, Joan Sayós ${ }^{4}$ and Natalia Lago ${ }^{1,5^{*}}$

\begin{abstract}
Background: It has recently become evident that activating/inhibitory cell surface immune receptors play a critical role in regulating immune and inflammatory processes in the central nervous system (CNS). The immunoreceptor CD300f expressed on monocytes, neutrophils, and mast cells modulates inflammation, phagocytosis, and outcome in models of autoimmune demyelination, allergy, and systemic lupus erythematosus. On the other hand, a finely regulated inflammatory response is essential to induce regeneration after injury to peripheral nerves since hematogenous macrophages, together with resident macrophages and de-differentiated Schwann cells, phagocyte distal axonal and myelin debris in a well-orchestrated inflammatory response. The possible roles and expression of CD300f and its ligands have not been reported under these conditions.

Methods: By using quantitative PCR (QPCR) and CD300f-IgG2a fusion protein, we show the expression of CD300f and its ligands in the normal and crush injured sciatic nerve. The putative role of CD300f in peripheral nerve regeneration was analyzed by blocking receptor-ligand interaction with the same CD300f-lgG2a soluble receptor fusion protein in sciatic nerves of Thy1-YFP-H mice injected at the time of injury. Macrophage M1/M2 polarization phenotype was also analyzed by CD206 and iNOS expression.

Results: We found an upregulation of CD300f mRNA and protein expression after injury. Moreover, the ligands are present in restricted membrane patches of Schwann cells, which remain stable after the lesion. The lesioned sciatic nerves of Thy1-YFP-H mice injected with a single dose of CD300f-IgG2a show long lasting effects on nerve regeneration characterized by a lower number of YFP-positive fibres growing into the tibial nerve after 10 days post lesion (dpl) and a delayed functional recovery when compared to PBS- or IgG2a-administered control groups. Animals treated with CD300f-IgG2a show at $10 \mathrm{dpl}$ higher numbers of macrophages and CD206-positive cells and lower levels of iNOS expression than both control groups. At later time points (28 dpl), increased numbers of macrophages and iNOS expression occur.
\end{abstract}

Conclusions: Taken together, these results show that the pair CD300f ligand is implicated in Wallerian degeneration and nerve regeneration by modulating both the influx and phenotype of macrophages.

Keywords: Regeneration, Immunoreceptors, CD300, Macrophage M1/M2 phenotype, Schwann cell, Wallerian degeneration, Phagocytosis

\footnotetext{
* Correspondence: nlago@pasteur.edu.uy

${ }^{\dagger}$ Equal contributors

'Neuroinflammation and Gene Therapy Laboratory, Institut Pasteur

Montevideo, Mataojo 2020, CP 11400 Montevideo, Uruguay

${ }^{5}$ Neurodegeneration Laboratory, Institut Pasteur Montevideo, Montevideo,

Uruguay

Full list of author information is available at the end of the article
} 


\section{Introduction}

Although axons in the peripheral nervous system (PNS) have the capacity to regenerate and reach distal targets after a mechanical injury, functional recovery is usually not complete [1]. Successful axonal regeneration and functional reinnervation depends on different factors such as severity and site of nerve injury, age of the subject, and the distance that axons have to grow until they reach distal targets, among others [2, 3].

After a peripheral nerve injury, the distal portion of the nerve undergoes progressive degeneration in a process called Wallerian degeneration (WD) [4]. While WD in the PNS is fast, taking 14-21 days to clear axonal and myelin debris, it is dramatically slow in the central nervous system (CNS) [5]. This fact has suggested that slow or deficient myelin and debris clearance from the injury site could create an inhibitory environment for axonal regeneration. Accordingly, $\mathrm{Wld}^{\mathrm{s}}$ mutant mouse with a delayed WD shows impairment of axonal regeneration [6, 7]. Thus, endogenous or therapeutic compounds increasing the speed of WD might enhance axonal regeneration and target reinnervation. WD begins with axonal degeneration, followed by myelin ovoid breakdown and myelin clearance by Schwann cells and resident and infiltrating macrophages $[8,9]$. The recruitment of resident macrophages to the injury site starts within hours while the infiltration of macrophages from blood begins 2-3 days after injury and peaks between 7 and 14 days $[10,11]$. Finally, myelin clearance is complete from 8 to 14 days after nerve injury [12]. Some authors have classified WD in a twostage process: the first one, an inflammatory process when pro-inflammatory cytokines such as IL-1 $\beta$ and TNF $\alpha$ are produced mainly by resident macrophages and Schwann cells, and a second stage of WD which aims at resolution of inflammation with secretion of anti-inflammatory cytokines such as IL-10 by infiltrated macrophages and Schwann cells [13-16]. New insights into macrophage activation related to macrophage polarization and their pro-inflammatory or anti-inflammatory responses have been reported $[17,18]$, and recently macrophages have been classified as M1 or "classically" activated macrophages and M2 or "alternatively activated" macrophages, depending on the profile of cytokines required for their activation $[19,20]$. Taken together, these data suggest that macrophages involved in WD might be polarized to the M1 phenotype on the first stage and to the M2 phenotype for the resolution of inflammation. Different markers have been suggested to be representative of the different phenotypes, such as CD206 (mannose receptor) or arginase I for M2 and iNOS or IL-1 $\beta$ for M1 phenotype [20, 21]. Despite this important breakthrough in activated macrophage classification, only few studies have been published describing the M1/M2 macrophage phenotype after a peripheral nerve injury [22, 23]. Overall, the differences seen between macrophage phenotype in the PNS and CNS could contribute to explain the differences between the effective WD process in the PNS in comparison with the CNS where WD is very slow and inhibitory factors for nerve regeneration remain in the damaged tissue. Thus, modulation of inflammation and macrophage polarization to a M1-M2 phenotype may represent a strategy to promote regeneration in the PNS and the CNS. However, additional studies are needed to firmly establish this hypothesis.

Activating/inhibitory immune receptors like CD200R, TREM2, and SIGLECs have been shown to mediate important functions in checkpoints for the modulation of neuroinflammation $[24,25]$. The CD300 family of activating/inhibitory receptors is composed in humans by six members that are able to form complexes on the cell surface through the interaction among their extracellular immunoglobulin domain [26-31]. Their combination in a complex differentially modulates the signaling outcome, suggesting a mechanism of how CD300 complexes could regulate the activation of myeloid cells upon interaction with their natural ligands [32]. All the CD300 family members share an extracellular region comprising a single Ig-like domain and were thought to have a myeloid lineage-restricted pattern of expression. However, the expression of CD300f was recently observed in microglia, oligodendrocytes, and neurons in vitro [33]. The importance of this family of receptors is highlighted by the fact that one of its members, CD300a, is the second gene with strongest evidence for positive selection between human and chimpanzee [34]. Moreover, CD300a and CD300f are among the genes with the highest upregulation after a spinal cord traumatic injury [33]. The CD300 family contains two inhibitory receptors, CD300a and CD300f, both displaying a long cytoplasmic tail with a variety of different tyrosine-based motifs, that are able to recruit phosphatases like SHP1 and SHP2 and therefore deliver inhibitory signals. The most interesting difference between these molecules, besides their different pattern of expression, is the existence of two binding motifs for the p85 subunit of PI3Kinase in the cytoplasmic tail of CD300f. In fact, it has been shown that CD300f delivers in vitro both inhibitory and activating signals, thus revealing a remarkable functional duality of this receptor [28, 35-38]. However, in vivo CD300f has shown to be mainly an inhibitory receptor, as shown in CD300f knockout animals using the experimental autoimmune encephalomyelitis (EAE) model of multiple sclerosis [39] and very recently in several models of allergy [40] and systemic lupus erythematosus [36]. This latter study shows that mouse CD300f (CLM-1) recognized outer membrane phosphatidylserine and 
regulated the clearance of apoptotic cells, being macrophages derived from CD300f knockout mice deficient for phagocytosis of apoptotic cells. Other recent reports suggest the existence of other main ligands for mouse CD300f, as phosphatidylcholine or ceramide [40, 41], and for human CD300f (IREM1), as sphingomyelin [42]. Despite the importance of CD300f in the regulation of inflammation and clearance of cell debris and apoptotic cells, no data is available regarding the expression of CD300f or its ligands in the normal and lesioned nerve and its role in regeneration.

In the present work, we characterize peripheral nerve expression of CD300f after a crush injury and the presence of its ligands. Moreover, by using soluble receptor fusion protein CD300f-IgG2a, we show that the blockade of the interaction between the immunoreceptor and its ligands impairs axonal regeneration and modulates macrophage M1/M2 phenotype.

\section{Materials and methods}

\section{Animal surgery and treatment}

Both male and female adult (8-12 weeks old) Thy1yellow fluorescent protein mice, line $\mathrm{H}$ (Thy1-YFP-H; Jackson Laboratories, Bar Harbor, USA) [43], were used in these studies. All experimental procedures were approved by the IPMon Animal Care Committee and conducted according to international FELASA guidelines, national law, and ethical guidelines (Uruguayan Animal Care Committee).

The surgical procedure was carried out following sterile precautions. Mice were anesthetized with ketaminexylazine $(90-10 \mathrm{mg} / \mathrm{kg}$ ) and the right sciatic nerve at the mid thigh level was exposed. Treatments were performed by direct injections at $45 \mathrm{~mm}$ from the tip of the third digit in $2 \mu \mathrm{l}$ of sterile PBS, using a fine glass micropipette connected to a Hamilton syringe. Immediately after the injection and at the same position, the nerve was crushed in two different directions $30 \mathrm{~s}$ each time with fine forceps. The crush site was labeled with lamp black powder. The wound was closed with 5-0 mononylon Ethilon sutures (Ethicon) and disinfected. The sciatic and tibial nerves and the plantar skin were harvested at $24 \mathrm{~h}, 3,10$, and 28 days post lesion (dpl).

All nerve injections were performed in $2 \mu \mathrm{PBS}$ and at $10 \mu \mathrm{g} / \mathrm{ml}$ concentration of the following products: rCD300f-IgG2a (rat extracellular domain of CD300f fused to mouse IgG2a protein) or purified mouse myeloma IgG2a (Invitrogen, Cat. $\mathrm{N}^{\circ}$ 026200).

\section{Histological and immunohistochemical procedures}

At 10 and 28 days post lesion ( $\mathrm{dpl}$ ), mice were deeply anesthetized with pentobarbitone and intracardially perfused with saline followed by $4 \%$ paraformaldehyde in $0.1 \mathrm{M}$ phosphate buffer solution. The sciatic nerve, including its main tibial branch, was dissected to the ankle level and harvested. A sciatic nerve segment $3 \mathrm{~mm}$ distal to the injury site was postfixed in $4 \%$ paraformaldehyde for $3 \mathrm{~h}$, transferred to $30 \% \mathrm{su}-$ crose, and frozen for further immunohistochemistry procedures. The tibial nerve was sampled in two, one segment of approximately $14 \mathrm{~mm}$ was washed with PBS $0.01 \mathrm{M}$ and whole mounted on slides in Mowiol mounting medium, whereas another segment of $2 \mathrm{~mm}$ at the ankle level was dissected out, postfixed in $2 \%$ glutaraldehyde in $0.1 \mathrm{M}$ phosphate buffer, and processed for embedding in Epon resin for semithin section preparations.

The sciatic nerve was cut longitudinally in the cryostat (8 $\mu \mathrm{m}$ thickness) and stored at $-20{ }^{\circ} \mathrm{C}$ until used. Non-specific antibody binding was blocked with PBS $0.01 \mathrm{M}+1 \%$ Triton $+10 \%$ fetal bovine serum for $1 \mathrm{~h}$ at room temperature. Sections were then incubated overnight at room temperature with the following primary antibodies: rabbit anti-Iba-1 (1:3000; Wako 019-19741), rat anti-mouse CD206 (1:500; Serotec MCA2235), rabbit anti-iNOS (1:500; Calbiochem 482728), and rat anti-mouse F4/80 (1:150; Serotec MCA497). Macrophages were also demonstrated using biotinylated Licopersicon esculentum (tomato) lectin (6 $\mu \mathrm{g} / \mathrm{ml}$; L9389; SigmaAldrich). After washes with PBS-Triton $1 \%$, sections were incubated for detection with appropriate secondary antibodies (Invitrogen) and DAPI. Controls were made to rule out nonspecific staining by incubation without the primary antibody.

For the recognition of mouse CD300f ligand, immunohistochemical stainings using a soluble fusion protein containing the extracellular domain of rCD300f fused to the $\mathrm{Fc}$ region of the IgG2a mouse heavy chain or control mouse IgG2a were performed (both at $10 \mu \mathrm{g} / \mathrm{ml}$ ). The studies were done in teased fibres and cryostat sections.

For immunohistochemistry of teased fibres, sciatic nerves were freshly dissected out and immediately immersed in $4 \%$ paraformaldehyde in $0.1 \mathrm{M}$ phosphate buffer for $3 \mathrm{~h}$. After washing with PBS, the perineural sheath was removed and nerve bundles were separated using a pair of fine needles. Teased fibres were blocked with PBS $0.01 \mathrm{M}+1 \%$ Triton $+10 \%$ fetal bovine serum for $1 \mathrm{~h}$ at room temperature and then incubated with the following primary antibodies: rabbit anti-MBP (1:100; Sigma-Aldrich M3821), rat anti-S100 (1:200; SigmaAldrich HPA006462), and rCD300f-IgG2a $(10 \mu \mathrm{g} / \mathrm{ml})$, overnight at room temperature. After washes with PBSTriton $1 \%$, sections were incubated for detection with appropriate secondary antibodies (Invitrogen) and DAPI.

For quantification of skin innervation, plantar pads of the hindpaw were removed at $28 \mathrm{dpl}$ and processed as described [44]. Briefly, after being postfixed in $4 \%$ paraformaldehyde and cryopreserved, $70-\mu \mathrm{m}$ cryostat sections 
were obtained. Non-specific antibody binding was blocked with PBS $0.01 \mathrm{M}+0.3 \%$ Triton $+1 \%$ normal goat serum for $1 \mathrm{~h}$ at room temperature. Sections were then incubated in primary rabbit antiserum against protein gene product 9.5 (PGP9.5, 1:1000; Ultraclone) for $48 \mathrm{~h}$ at $4{ }^{\circ} \mathrm{C}$. After several washes, sections were incubated for detection with appropriate secondary antibodies for $24 \mathrm{~h}$ at $4{ }^{\circ} \mathrm{C}$ and mounted on gelatin-coated slides. Five sections from each sample were used to quantify the number and density of nerve fibres present in the epidermis of the paw pads.

Tissue sections were examined using an Olympus IX81 microscope and images of the longitudinal sections were acquired at $20 \times$ with an AxioCam MRm Zeiss camera attached to a computer for further counts and imaging processing by using ImageJ software. Confocal images of teased fibres were acquired using a Leica TCS SP5 II confocal microscope.

Semithin sections $(1 \mu \mathrm{m})$ were obtained from the tibial nerve blocks. Images of whole tibial nerve cross section were acquired at 10x with an AxioCam MRm Zeiss camera attached to a computer, while sets of images chosen by systematic random sampling of squares representing at least $30 \%$ of the nerve cross-sectional area were acquired at 100x. Measurements of the crosssectional area of the whole nerve as well as counts of the number of myelinated fibres were carried out by using ImageJ software.

\section{Flow cytometry}

Cell surface expression of the CD300f (CLM-1) was tested by indirect immunofluorescence following standard techniques using a monoclonal anti-CLM-1 from hamster and the corresponding isotypic control [37, 39]. Cells from uninjured and crushed sciatic nerve were analyzed by flow cytometry at 3,10 , and $28 \mathrm{dpl}$ as described previously [45] with some modifications. Briefly, animals were perfused with PBS to eliminate blood. Crushed sciatic nerves were harvested, cut in little pieces, and passed through a cell strainer of $70 \mu \mathrm{m}$ and the cell suspension centrifuged. Samples were incubated with anti-mouse CD16/CD32 (1:100; Biolegend, Cat $\mathrm{N}^{\circ} 101319$ ) for $15 \mathrm{~min}$ at $4{ }^{\circ} \mathrm{C}$ to block the nonspecific binding of immunoglobulins to the Fc receptors. Cells were incubated with CD45-PerCP (Biolegend), CD11bPE-Cy7 (Biolegend), F4/80-APC (eBioscience), and monoclonal hamster anti-CLM-1 antibody $(5 \mathrm{ug} / \mathrm{mL})$ which was a generous gift from Genentech (San Francisco, CA) or an isotypic control (armenian IgG hamster from Serotec, Cat $\mathrm{N}^{\circ} \mathrm{MCA2356)}$, in PBS for $30 \mathrm{~min}$ at $4{ }^{\circ} \mathrm{C}$. After washing in PBS, cells were incubated with an anti-armenian hamster IgG-FITC secondary antibody (Biolegend, Cat N405502) in PBS for $30 \mathrm{~min}$ at $4{ }^{\circ} \mathrm{C}$ (dilution 1:100). Samples were analyzed with BD FACSCanto II Flow Cytometer and FlowJo Software (BD Biosciences).

\section{Evaluation of axonal regeneration}

Tibial nerves from crushed sciatic nerves at $10 \mathrm{dpl}$ were whole mounted onto microscope slides and coverslipped in Mowiol mounting medium. The number of YFPpositive fibres was visualized using an Olympus IX81 microscope. Regenerating axons were counted at 1-mm increments along the length of the tibial nerve beginning at $8-9 \mathrm{~mm}$ from the crush injury site. All evaluations were conducted by a researcher blinded to the treatment groups as described [46].

\section{Functional evaluation}

The walking track sciatic functional index (SFI) test was also carried out to assess recovery of locomotor function. The plantar surface of the mouse hindpaws was painted with black ink prior to crossing a runway. Footprints corresponding to the operated and intact paws were easily identified. The print length (PL) and the distance between the first and fifth toes (toe spread, TS) and between the second and fourth toes (intermediate toe spread, IT) were measured. The three parameters were combined in the SFI [47] to quantify changes in walking patterns. The SFI varies between 0 (for uninjured) and -100 (for maximal impaired gait). The walking track test was carried out prior to surgery to obtain baseline scores and then on days $4,7,10,14,17$, and 28 $\mathrm{dpl}$ to assess the recovery of locomotor function. A researcher blinded to the treatment groups conducted all evaluations.

\section{Isolation of RNA and QPCR}

Previous to nerve harvesting, animals were perfused with ice-cold PBS to eliminate blood. Due to very low RNA recovery from each nerve, the RNA was isolated and purified from pooled homogenized nerves (from $1 \mathrm{~mm}$ proximal to $6 \mathrm{~mm}$ distal to the crush, $n=6$ per group as described in [48] in TRIzol (SIGMA, T9424), and the aqueous phase was further purified using the Nucleospin RNA II Kit with RNase Free DNase treatment (Macherey Nagel 740955.50). RNA samples were reverse transcribed using M-MLV reverse transcriptase (Invitrogen 28025013) and random primers. Quantitative PCR (QPCR) was performed using the following TaqMan reagents from Invitrogen/Applied Biosystems: TaqMan Fast Advanced Master Mix (1205919), exon-spanning probes for CD300f/ CLM1 (Mm00467508_m1), IL-1b (Mm01336189_m1), iNOS (Mm00440502_m1), MRC1 (Mm00485148_m1), and IL-10 (Mm00439614_m1). The relative expression ratio is calculated using the real-time PCR efficiencies and the crossing point deviation of an unknown sample versus a control according to Pfaffl [49]. Eucariotic 18S RNA 
endogenous control (FAM-MGB 4333760) was included in the model to standardize each reaction run with respect to RNA integrity and sample loading. QPCR was performed using the Corbett Rotorgene 6000 apparatus and software. Cycling conditions were $50{ }^{\circ} \mathrm{C}$ for $2 \mathrm{~min}$, $95{ }^{\circ} \mathrm{C}$ for $10 \mathrm{~min}$, followed by 45 cycles at $95{ }^{\circ} \mathrm{C}$ for $15 \mathrm{~s}$ and $60{ }^{\circ} \mathrm{C}$ for $1 \mathrm{~min}$. [48].

\section{Production of rCD300f-IgG2a}

Chinese hamster ovary (CHO-K1) cells were stably transfected with pSecTag/mIgG2a constructs [26] and positive cells were selected with $250 \mathrm{mg} / \mathrm{mL}$ of Zeocin (Invivogen, San Diego, CA, USA). The chimerical protein was purified from the supernatant using a protein A-sepharose column (GE Healthcare, Pittsburgh, PA, USA) as described before [26].

\section{Phagocytosis assay}

Ten days after the crush injury and the different treatments, mice were anesthetized and approximately $8 \mathrm{~mm}$ of the lesioned nerve distal to the injury site was obtained, epineurium dissected and discarded, and incubated in PBS + collagenase $(2 \mathrm{mg} / \mathrm{ml})$ for $30 \mathrm{~min}$ at $37{ }^{\circ} \mathrm{C}$. After homogenization, single-cell suspensions from each nerve in separate wells were plated for $2 \mathrm{~h}$ in DMEM supplemented with $10 \%$ fetal bovine serum and penicillin $100 \mathrm{U} / \mathrm{ml}$, streptomycin $100 \mu \mathrm{g} / \mathrm{ml}$ and in the presence of fluorescent beads (1:1000; Life Technologies, F-8762). After several washes, cells were fixed in $4 \%$ PFA and the number of beads per cell were quantified under epifluorescence microscope observation by a treatment-blinded researcher.

\section{Data processing and statistical analysis}

All data are shown as mean \pm standard error of the mean (SEM). Statistical analysis of behavioral data (SFI) was determined using two-way repeated measures ANOVA followed by Bonferroni post hoc analysis. Oneway analysis of variance (ANOVA) followed by Tukey's post hoc analysis was used for experimental data with more than two experimental groups. A value of $p \leq 0.05$ was considered to be statistically significant.

\section{Results}

\section{CD300f expression in the sciatic nerve after injury}

Expression of the immune receptor CD300f in the sciatic nerve was assessed by QPCR and flow cytometry in control uninjured and crush lesioned samples. Low basal CD300f mRNA expression was detected; its levels increased at 1 day post lesion $(\mathrm{dpl})$, peaking at $3 \mathrm{dpl}$ and declining thereafter, showing at $28 \mathrm{dpl}$ slightly lower levels than at $1 \mathrm{dpl}$ but still remaining high in comparison with uninjured nerves (Fig. 1a). Protein expression of CD300f and several macrophage markers
(F4/80, CD45, and CD11b) were analyzed by flow cytometry in uninjured and crushed sciatic nerves at 3 , 10, and $28 \mathrm{dpl}$ (Fig. 1b-e). A small proportion of resident $\mathrm{CD} 45+/ \mathrm{CD} 11 \mathrm{~b}+/ \mathrm{F} 4 / 80+$ macrophages expressed CD300f in the uninjured nerve (Fig. 1e). After crush sciatic nerve lesion, there was an increase in the total number of $\mathrm{CD} 45+/ \mathrm{CD} 11 \mathrm{~b}+/ \mathrm{F} 4 / 80+$ macrophages present in the injured nerve in comparison with a non-injured nerve. Nearly $40 \%$ of these macrophages expressed CD300f at $3 \mathrm{dpl}$, and the expression declined progressively to $28 \mathrm{dpl}$. Moreover, few F4/80 negative and $\mathrm{CD} 11 \mathrm{~b}+/ \mathrm{CD} 45+$ positive cells at 3 and $10 \mathrm{dpl}$ also expressed CD300f, most probably representing neutrophils and maybe mast cells (not shown).

\section{CD300f ligand is expressed in the PNS}

In order to characterize the presence of the ligand of CD300f in the PNS, we performed immunohistochemical studies using rCD300f-IgG2a fusion protein as described [50] on both frozen sections and teased fibres. Uninjured teased fibres from Thy1-YFP-H transgenic mice showed a punctate staining pattern with rCD300fIgG2a, not co-localizing with the axonal cytoplasm (Fig. 1f). While no co-localization was observed at the MBP-positive myelin domain of Schwann cells (Fig. 1g), partial co-localization with the external limit of S100positive Schwann cell domain was apparent (Fig. 1h). Frozen sections of crushed sciatic nerve were used in order to assess the expression of the ligand after the injury. At $10 \mathrm{dpl}$, no apparent difference was observed in the staining for the ligand in comparison with an uninjured nerve (Fig. 1i, j). No staining was detected using IgG2a negative control (Fig. 1k).

\section{CD300f participates in axonal regeneration}

In order to evaluate the role of $\mathrm{CD} 300 \mathrm{f}$ in regeneration after a crush nerve injury, the crushed sciatic nerve of Thy1-YFP-H transgenic mice was injected with a single dose of soluble CD300f-IgG2a at the moment of the injury. CD300f receptor-ligand interaction blocked in this way has been shown to render identical results compared to CD300f knockout animals [39, 40]. Axonal regeneration at $10 \mathrm{dpl}$ was evaluated by counting the number of YFP-positive fibres growing through the tibial nerve as previously reported $[46,51]$. In transgenic YFP$\mathrm{H}$ mice, approximately $3 \%$ of myelinated peripheral nerve fibres are YFP positive, with approximately $58 \%$ of them being sensory axons and $42 \%$ motor axons [52]. Consequently, Thy1-YFP-H mice have provided a valuable tool for studies of Wallerian degeneration [53] and nerve regeneration $[46,51,52,54]$. When lesioned sciatic nerves were injected with CD300-IgG2a, a significant lower number of regenerating axons growing long distances were observed compared to both mIgG2a and 


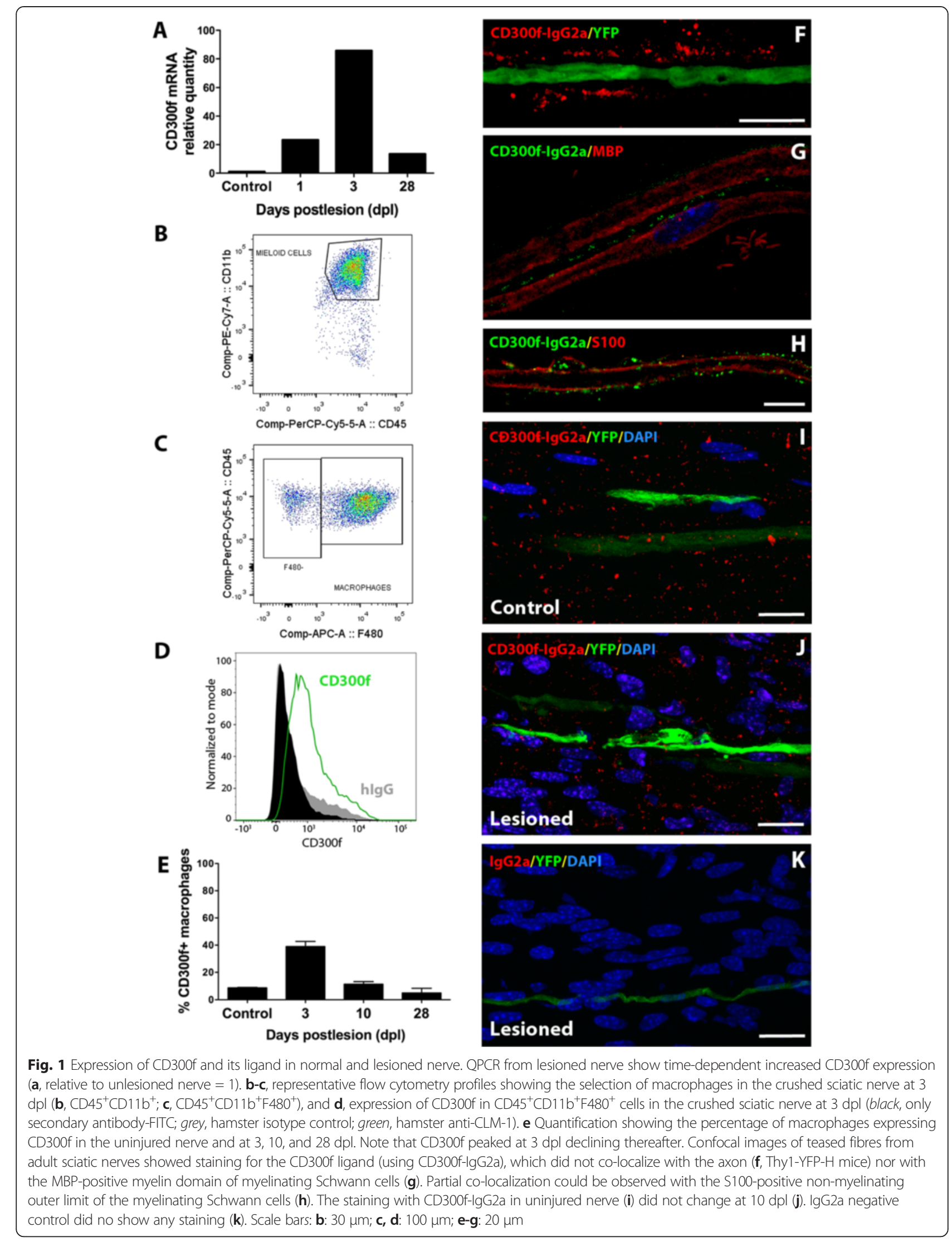


PBS control groups (Fig. 2a, b). We further evaluated the recovery of function after crush injury by analyzing the hindpaw prints to obtain the SFI. After crush sciatic nerve injury, the SFI drops to $-80 \%$ whereas it recovers by day 28 up to $-20 \%$ with no significant differences when compared to pre-injury values. After CD300fIgG2a treatment, a strong tendency $(p=0.07)$ towards delayed functional recovery was observed compared to
IgG2a control animals (Fig. 2c). A detailed study of regenerated fibres was performed at $28 \mathrm{dpl}$ by analyzing the number of regenerated myelinated fibres counted in semithin sections in the tibial nerve at the ankle level, and no differences between groups were observed (Fig. 2d). In addition, distal re-innervation was assessed by counting the number of PGP9.5-positive fibres in the epidermis. The number of PGP9.5-positive fibres was

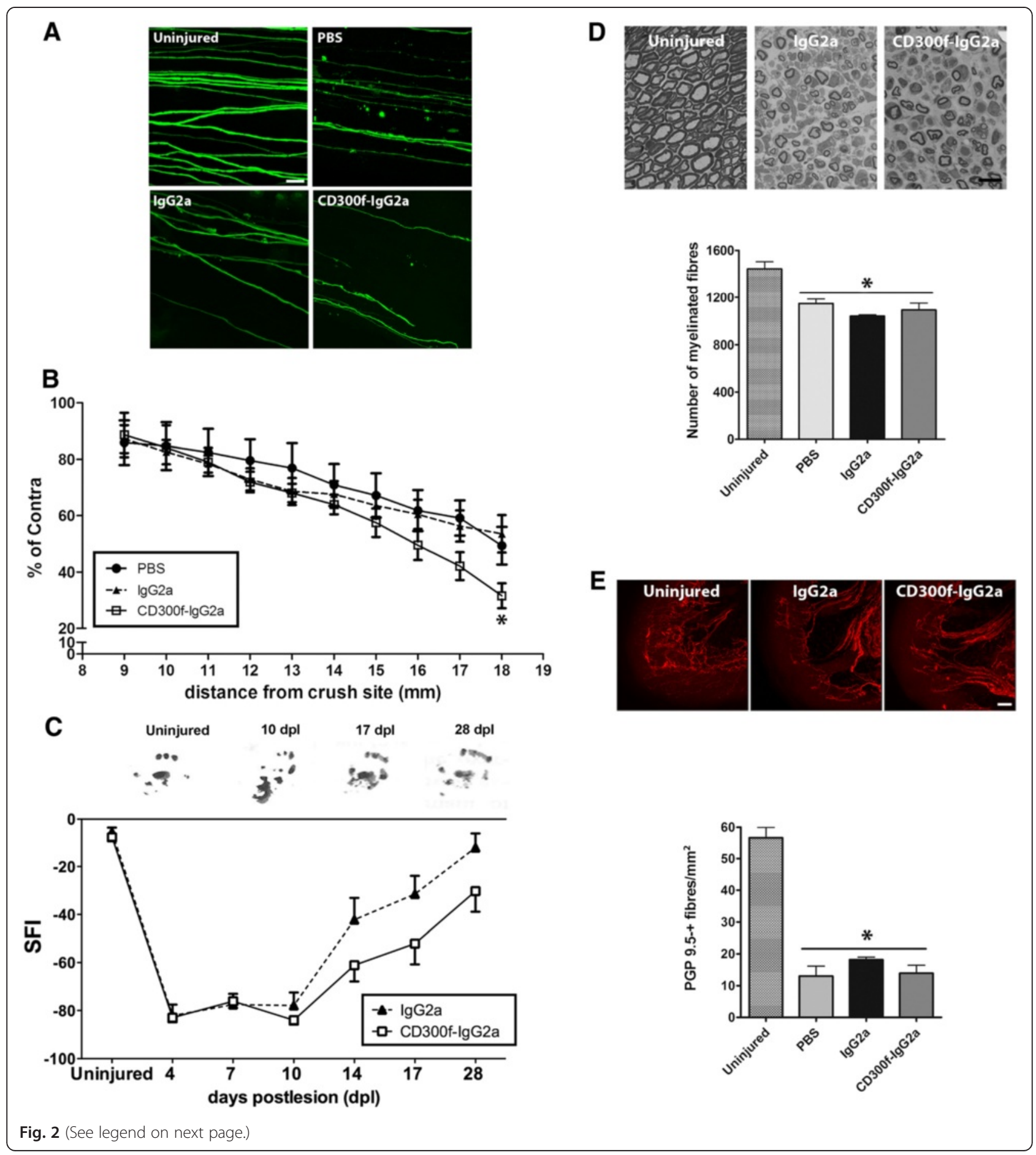


(See figure on previous page.)

Fig. 2 CD300f-IgG2a slows down axonal regeneration at 10 days after a sciatic nerve crush injury. Confocal images of whole mount tibial nerve at $18 \mathrm{~mm}$ distal from the crush site of uninjured or injured and injected nerves at $10 \mathrm{dpl}$ (a). Thinner regenerating axons are seen in the tibial nerve (IgG2a and CD300f-IgG2a) compared with uninjured nerves. The group treated with the soluble receptor CD300f-IgG2a shows less axons growing distally through the tibial nerve than the IgG2a control group. $\mathbf{b}$ YFP-positive axons numbers are expressed as the percentage of contralateral axons at the indicated distance from the crush site at $10 \mathrm{dpl}\left(n=8\right.$ animals per group; ${ }^{*} p<0.05$ vs. PBS and IgG2a). Representative footprints obtained from uninjured and at 10, 17, and $28 \mathrm{dpl}$ are shown (c). The Sciatic Functional Index (SFI) walking track analysis revealed a strong tendency $(p=0.07)$ towards delayed functional recovery after treatment with CD300f-IgG2a when compared to IgG2a control animals ( $n=8$ mice per group). Representative micrographs of transverse sections of an uninjured sciatic nerve and at 28 days after crush injury and injection of IgG2a or CD300f-IgG2a show regenerated axons with thinner myelin at $28 \mathrm{dpl}$ (d). Quantification shows a decreased number of myelinated axons in the tibial nerve with significantly fewer myelinated fibres in all crush injured animals ( ${ }^{*} p<0.05$ vs. uninjured group). The analysis of skin innervation at $28 \mathrm{dpl}$ by the quantification of the number of intraepidermal nerve fibres in the plantar skin immunolabeled against protein gene product 9.5 (PGP 9.5) showed a significant reduced number of nerve fibres after crush injury, but no differences were observed between treated groups ( ${ }^{*} p<0.05$ vs. uninjured group). Scale bars: a, e $50 \mu \mathrm{m} ; \mathbf{d} 10 \mu \mathrm{m}$

significantly lower in injured groups than in the contralateral skin at $28 \mathrm{dpl}$ but no differences were seen between treatments (Fig. 2e). Taken together, these data show that a single injection of the soluble CD300f-IgG2a transiently delayed the regeneration, followed by endogenous compensations that achieve normal regeneration at longer time points.

\section{Blocking CD300f/ligand interaction induced macrophage accumulation and changes in phenotype}

In order to understand the mechanism of impaired regeneration by blocking CD300f function, we assessed the level of inflammatory markers and macrophage infiltration and phenotype. QPCR from nerve samples at $1 \mathrm{dpl}$ showed increased mRNA for IL-1 $\beta$, iNOS, CD206, and IL-10 when compared to uninjured nerves (Fig. 3a). However, no significant differences were observed after the injection of CD300f-IgG2a or IgG2a. Moreover, the blockade of CD300f/ligand interaction did not alter CD300f mRNA at $1 \mathrm{dpl}$. Interestingly, later on at $10 \mathrm{dpl}$, immunohistochemistry against the general macrophage marker tomato lectin in the sciatic nerve distally to the crush showed increased numbers of positive cells with the typical morphology of phagocytic macrophages, which were further increased by treatment with CD300fIgG2a (Fig. 3b, c). Similar results were obtained with anti-Iba-1 general macrophage marker (not shown). At $28 \mathrm{dpl}$, phagocytic macrophages could still be seen in the sciatic nerve although at lower numbers than at 10 dpl (Fig. 3c). However, in the group injected with CD300f-IgG2a, macrophages remained at significantly higher numbers than in the control group.

We further evaluated whether the blockade of the interaction between CD300f and its ligand had an effect in the phenotype of the macrophages that infiltrated into the nerve. We performed immunohistochemistry against the mannose receptor (CD206) as a marker of alternative M2 macrophages and against iNOS as a marker of classical proinflammatory M1 macrophages. iNOS labeling was significantly reduced in animals treated with rCD300f-IgG2a at $10 \mathrm{dpl}$ but increased at $28 \mathrm{dpl}$ in comparison with the injured control group (Fig. 3d, e).

CD206 labeling of the uninjured and IgG2a-treated nerves showed a low number of CD206-positive cells scattered through the nerve without differences between uninjured and injured nerves at $10 \mathrm{dpl}$. However, in the group of animals injected with rCD300-IgG2a, there was a significantly higher number of CD206-positive cells at $10 \mathrm{dpl}$ (Fig. 3f, g). At $28 \mathrm{dpl}$, the injured control group showed higher numbers of CD206-positive cells in comparison with uninjured nerves and control injured nerves at $10 \mathrm{dpl}$ but without significant differences between the injured control group and the rCD300fIgG2a-treated group. Interestingly, considering all the experimental groups together, the number of regenerating YFP-positive fibres negatively correlated with the number of CD206-positive cells at $10 \mathrm{dpl}$ (Spearman's rank test, $p=0.02, r=-0.64)$. This correlation was not observed at $28 \mathrm{dpl}$.

Tomato lectin has been widely used as a marker of microglia/macrophages and endothelial cells in the CNS $[55,56]$. Here, we show that tomato lectin is also a good marker for macrophages in the normal and lesioned nerve when compared to Iba- 1 and F4/80 (Figs. 4 and 5). Tomato lectin labeling increased from 3 dpl peaking at 10-14 days post lesion (Fig. 4) as published by other authors using other macrophages markers such as F4/80 and CD11b [10, 11]. Tomato lectin and Iba- 1 labeled the very few resident macrophages of the normal nerve (Fig. 4a-c). Interestingly, an important heterogeneity of macrophages was observed after the lesion. Most infiltrated large foamy macrophages at all time points were intensely stained with tomato lectin, Iba-1, and F4/80 markers (Figs. 4d-l and 5). However, smaller cells showed different combinations of stainings, including tomato lectin-positive and Iba-1 and F4/80negative staining. This latter category would also include the endothelial cells. Moreover, both Iba-1 and F4/80 


\section{A}

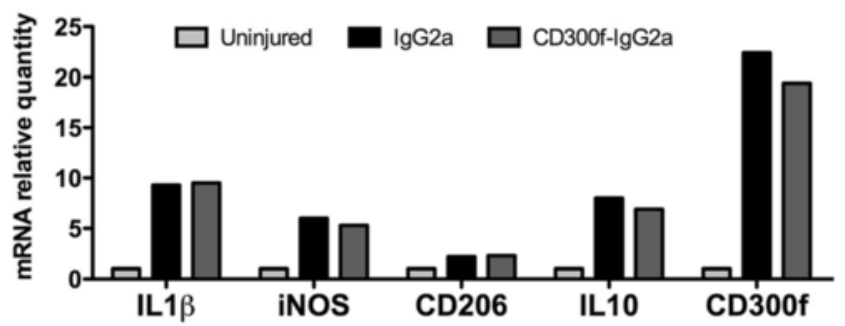

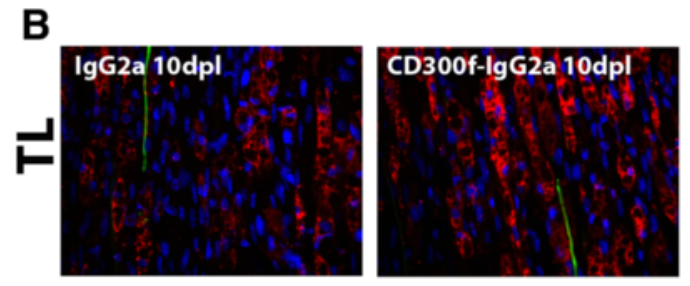

D

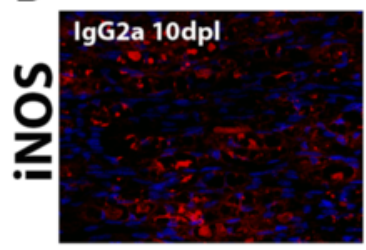

$\mathbf{F}$

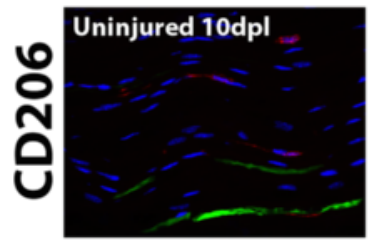

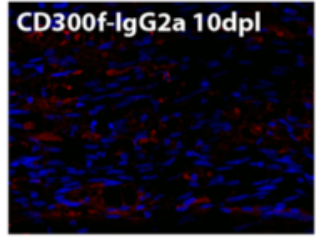
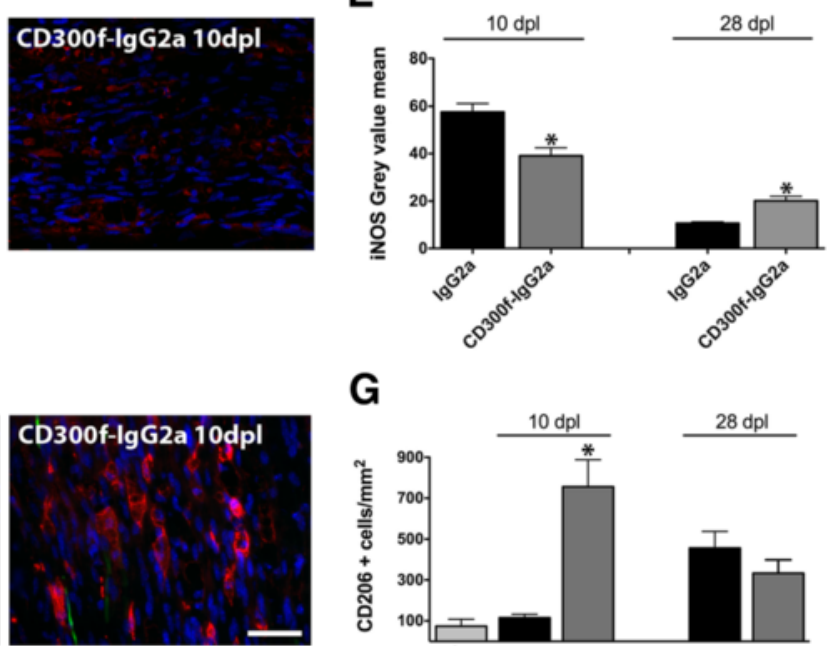

E

G

C
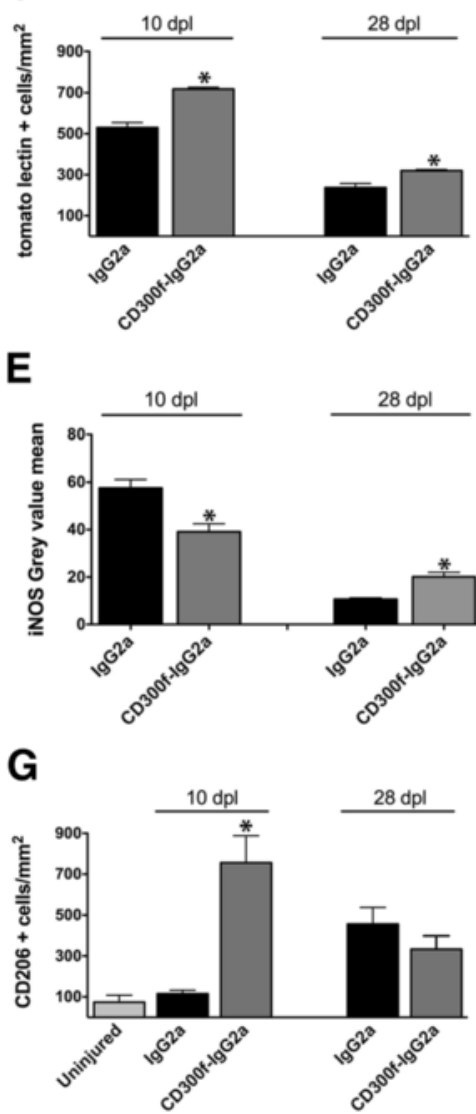

Fig. 3 CD300f-lgG2a increases macrophage infiltration and induces their phenotypic change after a sciatic nerve crush injury. QPCR shows an increase of several cytokines and CD300f at $1 \mathrm{dpl}$ with no differences between treatments (a). Infiltrated macrophages stained by tomato lectin show increased number at 10 and $28 \mathrm{dpl}$ following CD300f-IgG2a treatment (b, c). The macrophage phenotype is altered after CD300f-lgG2a treatment, showing decreased iNOS staining at $10 \mathrm{dpl}$ and increased staining at $28 \mathrm{dpl}$ (d, e: mean grey value). On the contrary, the number of CD206-stained cells shows an important increase at $10 \mathrm{dpl}(\mathbf{f}, \mathbf{g})$, but no significant differences at $28 \mathrm{dpl}$. YFP-regenerated myelinated fibres can be seen in green in $\mathbf{b}$ and $\mathbf{f}$. ( ${ }^{*} p<0.05$ vs. uninjured and lgG2a treatment). Scale bar in $\mathbf{b}$ and e: $40 \mu \mathrm{m}$

stained small macrophages that remained unstained with tomato lectin (Fig. $4 \mathrm{~d}-\mathrm{i}$ red arrows, Fig. 5 arrows). This macrophage phenotype heterogeneity could also be observed with M1/M2 markers like iNOS and CD206. Although most iNOS and CD206 staining co-localized with the big foamy tomato lectin and F4/80-positive macrophages (Fig. 5 arrowheads), round and smaller tomato lectin-negative and F4/80-positive macrophages also expressed iNOS or CD206 (Fig. 5 arrows). Taken together, these data show that all iNOS and CD206 staining was detected inside tomato lectin, Iba-1, or F4/80-positive cells.

\section{Phagocytosis after blockade of CD300f}

To further characterize the phenotype of inflammatory cells in the anti-regenerative milieu at $10 \mathrm{dpl}$ induced by CD300f-IgG2a, we analyzed the phagocytic activity of nerve cells. Acutely isolated nerve cells were incubated for $2 \mathrm{~h}$ with fluorescent beads and 


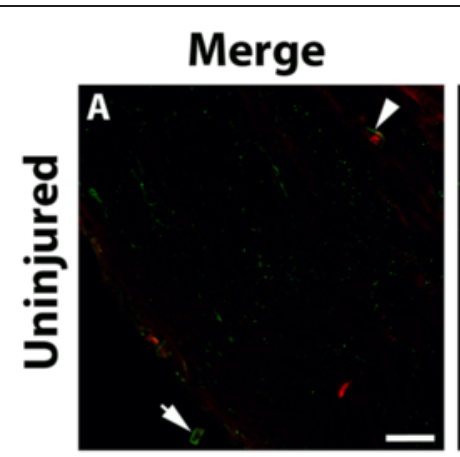

\section{Tomato Lectin}
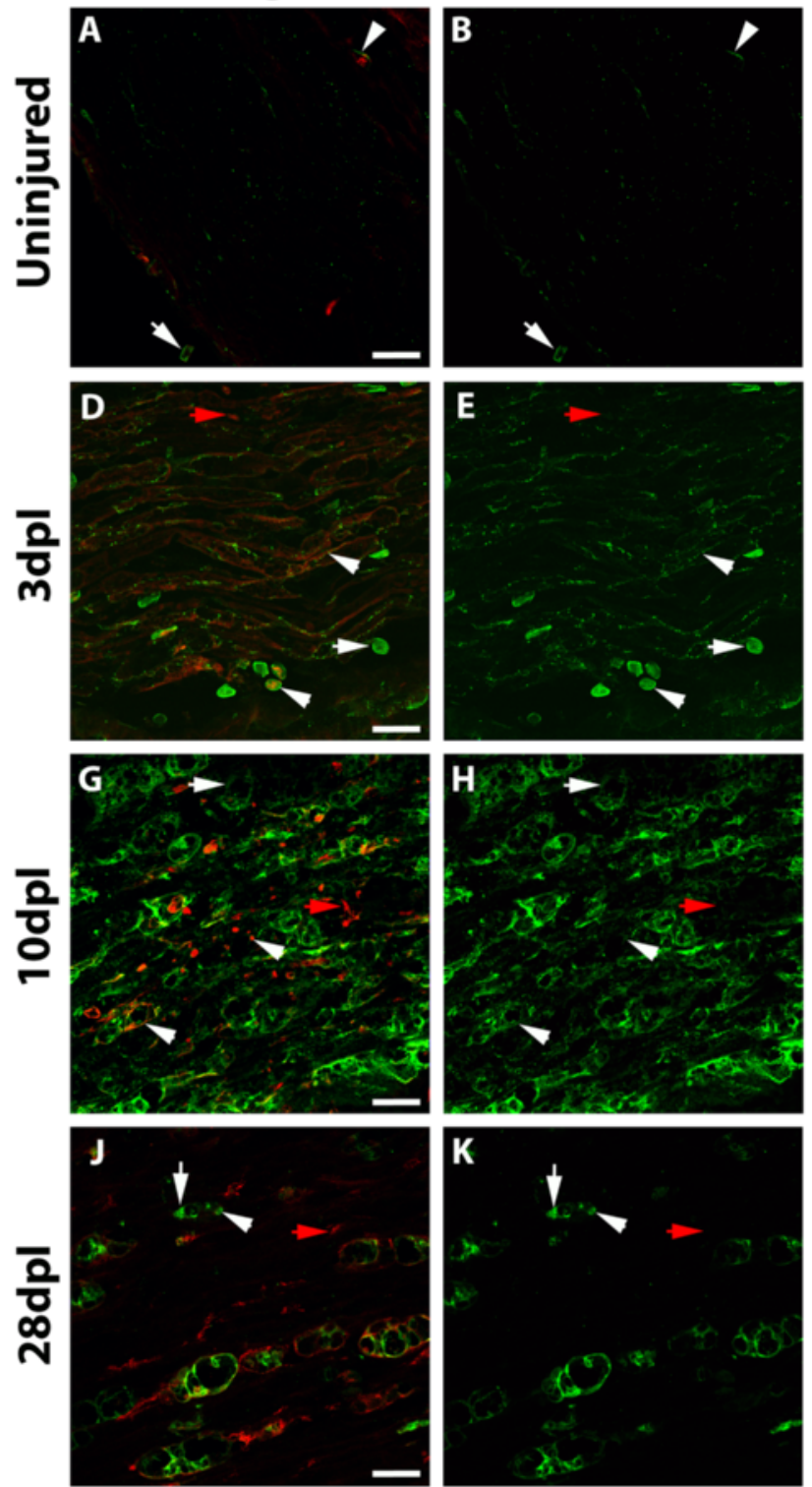

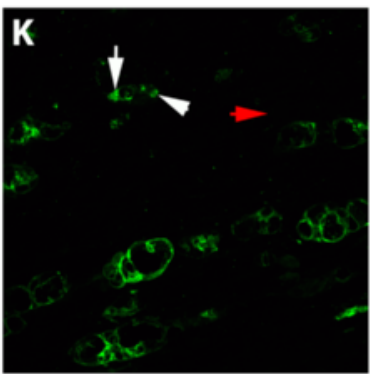

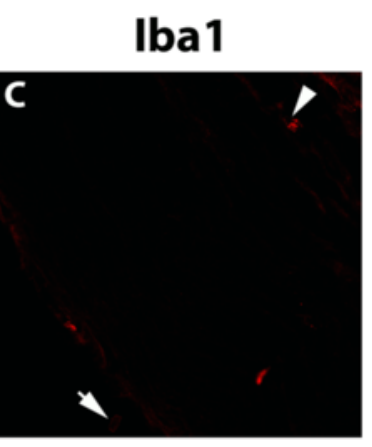
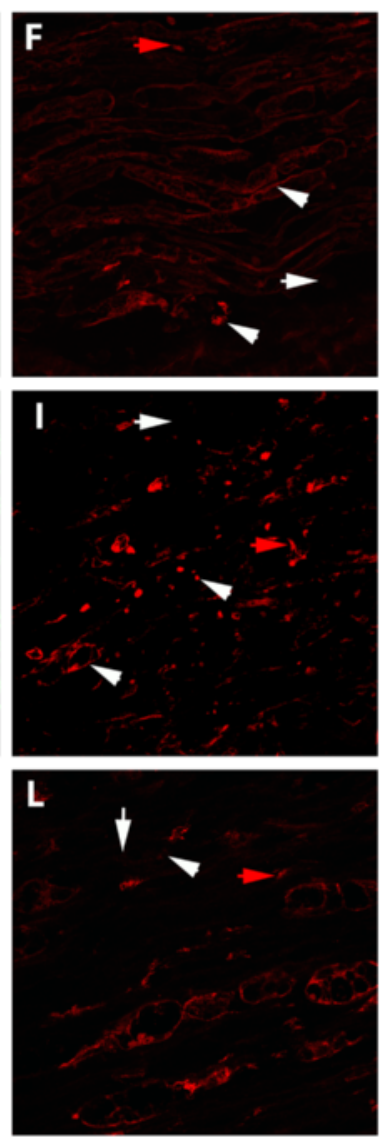

Fig. 4 Tomato lectin stains most of the macrophages in the normal and injured nerve. Single focal plane confocal microscopy showed tomato lectin staining for macrophages in the normal and lesioned nerve. Tomato lectin and Iba-1 labeled the very few resident macrophages of the normal nerve (a-c, arrowhead) and meninges (a-c arrow). An increase of tomato lectin and Iba-1 staining was observed at earlier time points after a crush injury $(3 \mathrm{dpl})$, which peaked at $10 \mathrm{dpl}$ and decreased by $28 \mathrm{dpl}(\mathbf{d}-\mathbf{I})$. Most macrophages were stained with both markers (a-l, arrowheads), including big foamy macrophages and some smaller and round macrophages. Interestingly, some cells were only stained with tomato lectin (d-I, white arrows) and other only stained with Iba-1 (d-I, red arrows). Scale bar: $20 \mu \mathrm{m}$

the number of beads/cell was quantified. The treatment of the nerve with CD300f-IgG2a at the time of the lesion, induced 10 days later, increased phagocytic activity of nerve cells when compared to IgG2a treatment. A reduction in the percentage of cells with $0-1$ phagocyted beads and an increase in the percentage of cells with 6-10 phagocyted beads were observed after CD300f-IgG2a treatment (Fig. 6).

\section{Discussion}

In the present work, we show that both CD300f and its ligands are present in the non-injured peripheral nerve, and that CD300f mRNA and protein are increased after a crush lesion. Interestingly, a single injection of the CD300f-IgG2a soluble fusion protein into the injured sciatic nerve delays both axonal regeneration at $10 \mathrm{dpl}$ and functional recovery but has no effects at long-term 

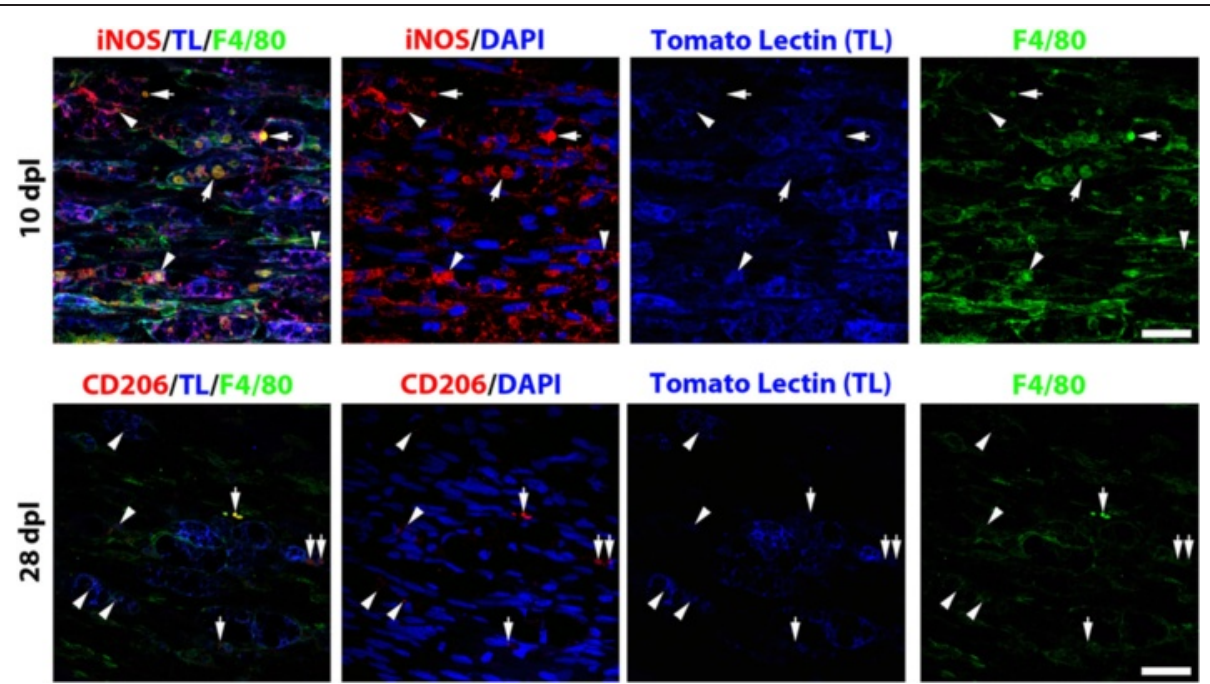

Tomato Lectin (TL)
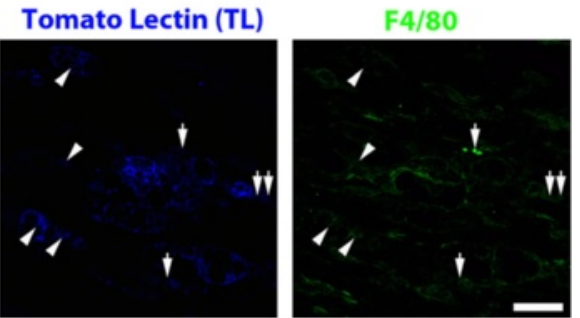

Fig. 5 iNOS and CD206 stain a heterogeneous population of macrophages. Single focal plane confocal microscopy for iNOS or CD206 combined with tomato lectin and F4/80 macrophage staining evidenced that most cells co-stain with tomato lectin and F4/80, and some of them are in addition iNOS or CD206 positive (arrowheads). Moreover, there is a population of round and smaller F4/80-positive and tomato lectin negative macrophages that also shows iNOS or CD206 staining (arrows). Scale bar: $20 \mu \mathrm{m}$

regeneration. This delayed regeneration is associated to a modulation in the number and phenotype of M1/M2 macrophages in the lesioned nerve.

Recent reports have shown that phospholipids as phosphatidylcholine or phosphatidylserine are ligands for CLM1 , the mouse orthologue of CD300f [35, 36, 41]. Phosphatidylserine/CLM-1 interaction contributes to apoptotic cell clearance and hence to dampen inflammation $[35,36]$. Ceramide has also been described as a putative ligand for this receptor, contributing to dampening inflammatory reactions of mast cells in several allergy models by the activation of CLM-1 negative signaling [40]. The interaction of activating/inhibitory immunoreceptors with lipids appears to be a more general phenomenon [41]. For instance, some gangliosides and 3-O-sulfo- $\beta$-d-galactosylceramide (C24:1) are potential ligands for CD300b/CLM-7 [57]. In the central nervous system, staining of the brain and spinal cord with rat or human CD300f-IgG2a showed a distinctive punctuate pattern, mainly in oligodendrocytes of the white matter [50]. Accordingly, we show here a similar punctuate staining pattern with CD300f-IgG2a in peripheral nerves. Interestingly, by using teased nerve fibres and Thy1-YFP-H mice, we evidence the specific subcellular localization of the CD300f ligands to what appears to be the outer cell membrane of the non-myelinating S100-positive domain of myelinating Schwann cells previously described [58] and not to the MBP-positive myelin sheath or the axonal compartment. However, we cannot discard the possibility that the ligand may also be present in non-myelinating Schwann cells or some component of the extracellular matrix. Although electron microscope procedures are necessary to determine its precise location, our confocal

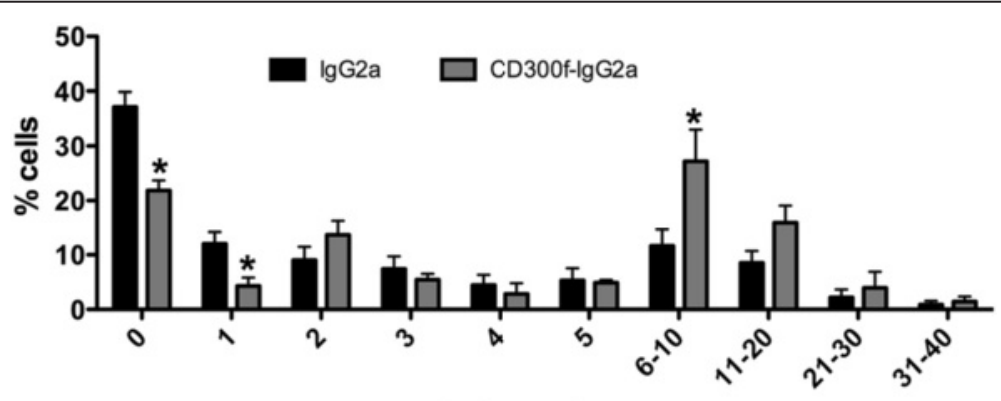

$\mathbf{N}^{\circ}$ of beads/cell

Fig. 6 CD300f-IgG2a increases phagocytosis at 10 days after a sciatic nerve crush injury. Nerve cells acutely isolated from the injured nerve at 10 dpl show enhanced phagocytosis of fluorescent beads after CD300f-lgG2a treatment compared to control IgG2a. A significant decrease of cells having phagocyted none or 1 bead and an increase in the number of cells having phagocyted $6-10$ beads was observed $\left(^{*} p<0.05\right.$ vs. lgG2a treatment) 
images suggest the localization of the ligand in the outer non-myelin Schwann cell membrane [58]. The normal presence of the ligands in Schwann cells and oligodendrocytes point to supplementary roles in addition to the phosphatidylserine "eat me" signal or the ceramideinduced signaling previously described. Other authors have shown that CD200, the ligand for the inhibitory immune receptor CD200R, is expressed in Schwann cells in the intact nerve [59]. In the CNS, this receptor induces a tonic anti-inflammatory signal contributing to set the threshold and magnitude of proinflammatory signaling $[24,60]$. Whether the ligand of CD300f expressed on Schwann cells and oligodendrocytes also contributes to the maintenance of this tonic anti-inflammatory state is an open question. Chang and co-workers showed that CD200 is downregulated after crush injury in the site of lesion [59]. They hypothesized that, after nerve injury, CD200 is downregulated in order to decrease immunosuppression and enhance influx of macrophages and the inflammatory response to eliminate myelin and axonal debris. The ligands for CD300f do not decrease at least at $10 \mathrm{dpl}$, suggesting different signaling mechanisms for these two receptors. Interestingly, despite intense invasion of macrophages into the nerve, a very similar staining pattern was observed for the CD300f ligands, suggesting that macrophages do not bear the ligand. In accordance, microglial cells in vitro did not stain with CD300f-IgG2a [50].

Recent findings suggest that the anti-inflammatory physiological state of most tissues is not only a passive state resulting from absence of inflammatory stimuli but an active condition that requires participation of several molecules responsible for the suppression of potentially inflammatory stimuli. Under this paradigm, a physiological function for the ligands of inhibitory receptors like CD200R, CD300a, or CD300f could be to contribute to the so-called "On" and "Off" signals [61]. "Off" signals are constitutively present in the brain parenchyma and are expressed mainly by healthy neurons, whereas "On" signals are expressed by endangered or impaired neurons [62]. The integration of all the inhibitory and activating inputs shapes the phenotype and response of microglial cells or macrophages accordingly. In fact, several activating and inhibitory receptors similar to CD300f like CD200R, TREM2, or SIGLECs have been reported to be key regulators of microglial and macrophage activation [24, 25]. Thus, these mechanisms, including CD300f and its ligands, could also be in place for the interaction of macrophages and Schwann cells in the normal and injured PNS to regulate the inflammatory status.

CD300f has been reported to deliver both activating and inhibiting signals [28, 35-37]. However, only inhibitory signals have been found on monocytic cell lines. For instance, crosslinking CD300f in the human THP1 monocytic cell line inhibited proinflammatory cell activation induced by several TLR ligands through a SHP1and SHP2-mediated mechanism [63]. The role of CD300f in the proinflammatory activation of primary human monocytes/macrophages in vitro has not been reported. Using CD300f-deficient mice in the EAE mouse model, it was shown that CD300f acts as a negative regulator of myeloid cell activity by suppressing the production of inflammatory cytokines, nitric oxide, and demyelination [39], confirming the negative anti-inflammatory signaling exerted by CD300f on monocyte/macrophages. After nerve injury, we show that CD300f mRNA was increased from $1 \mathrm{dpl}$, peaking at $3 \mathrm{dpl}$, and decreasing at $28 \mathrm{dpl}$. The expression of the protein was demonstrated by flow cytometry. We found protein expression in a subpopulation of macrophages in non-injured nerves and also after a crush injury, where the expression peaked at $3 \mathrm{dpl}$. Interestingly, we observed few F4/80 negative cells that showed CD300f expression, a staining that could represent neutrophils or mast cells. Accordingly, CD300f expression has also been shown in neutrophils [26, 31] and mast cells [40], both of which participate in nerve injury and regeneration. The time window of appearance of CD300f positive cells correlates with the influx rate of monocyte/macrophages and neutrophils into the lesioned nerve $[11,64,65]$. To assess the possible role of CD300f and its ligands after a peripheral nerve injury, we took advantage of the description that $\mathrm{CD} 300 \mathrm{f}$ receptor-ligand interaction could be blocked using CD300f-Fc fusion proteins, rendering identical results than those observed in CD300f knockout animals. For example, in the EAE model, CD300f-Fc worsened clinical scores to similar levels than CD300f KO mice $[39,40]$. Moreover, intradermal pretreatment with CD300f-Fc enhanced passive cutaneous anaphylaxis responses in wild type but not in CD300f $\mathrm{KO}$ mice [40]. These results suggest that the effect of CD300f-Fc proteins is mediated by dampening CD300f signaling by an uncoupling of CD300f and its ligand rather than by directly activating signaling by the interaction of the soluble CD300f-Fc with the ligand. Interestingly, we show that dampening CD300f signaling using the soluble CD300f-IgG2a fusion protein-induced accumulation of macrophages that displayed an M2 alternative activation phenotype including increased CD206 and decreased iNOS expression. Whether this is a direct effect of dampening macrophage CD300f signaling or an indirect effect remains to be elucidated. Despite injection of the soluble receptor CD300f-IgG2a at the moment of the lesion, no acute changes on mRNA for CD206, iNOS, IL$1 \beta$, IL-10, or endogenous CD300f were observed at 1 $\mathrm{dpl}$. This suggests a more complex and long lasting mechanism of Schwann cell and macrophage interactions 
determining the altered inflammatory response and delayed regeneration observed. In addition to the modulation of the proinflammatory phenotype, CD300f may also contribute to dampen inflammatory reactions promoting phagocytosis of apoptotic cells [36]. Phagocytosis of myelin and cell debris is a critical component of WD and successful regeneration [5]. The impaired regeneration after the single injection of CD300f-IgG2a might be related to inhibition of phagocytosis and thus delayed debris clearance. Accordingly, at $10 \mathrm{dpl}$, when no CD300f-IgG2a remains, the accumulation of debris may trigger the increased phagocytosis of nerve cells observed here that may be responsible for the delayed but successful regeneration at $28 \mathrm{dpl}$.

Despite the importance of macrophage phenotype in WD and axonal regeneration, only a few reports [22, 23] have described the expression of M1/M2 phenotypic cell markers after nerve injury and repair. In a recent paper, Ydens and colleagues made a description of the different markers of M1 and M2 macrophages after nerve transection and repair in mice, showing a rapid M2 polarization of macrophages after axotomy [22]. They evaluated a high number of markers of inflammation including iNOS, CD206, and IL-1 $\beta$ at different time points after nerve injury and mainly by QPCR. In accordance with our results, they observed a rapid fast induction of mRNA for IL-1 $\beta$ and IL-10 at $1 \mathrm{dpl}$. Moreover, they observed the upregulation of other M2 markers like Arg1, Ym1, or TREM2. They also reported that the mRNA for CD206 did not show changes at the different time points evaluated (until $14 \mathrm{dpl}$ ). In accordance, we did not observe notable changes in CD206 mRNA at $1 \mathrm{dpl}$ or in protein level at $10 \mathrm{dpl}$ in comparison with uninjured nerves. However, we also analyzed longer time points $(28 \mathrm{dpl})$ to sample processes of resolution of the neuroinflammation and found an increase in CD206 staining in comparison with both uninjured and $10 \mathrm{dpl}$ control injured sciatic nerves. This late increase might be a consequence of signals aimed to resolve inflammation by adjusting macrophage polarization towards a healing phenotype. In relation to M1 macrophage polarization after nerve injury, Ydens and colleagues did not show a significant change in iNOS, IL-12p40, or INF $\gamma$ mRNA levels at the different time points post lesion studied. However, in the present work, we have seen a significant increase in the iNOS mRNA at $24 \mathrm{~h}$ after lesion and in the iNOS protein at 10 and $28 \mathrm{dpl}$. These differences in the results could be due to the type of nerve lesion used between the two studies, i.e., nerve section or nerve crush. Further experiments are needed to establish the effect of the different M1/M2 markers on nerve neuroinflammation and regeneration. In this line, we show that the manipulation of the CD300f/ ligand interaction induces impairment of regeneration associated to important changes in M1/M2 markers. After a sciatic nerve crush injury, a single injection of CD300f-IgG2a significantly increased the number of tomato lectin-positive macrophages and CD206-positive cells and decreased iNOS immunoreactivity at $10 \mathrm{dpl}$, whereas an opposite effect was found at $28 \mathrm{dpl}$. These data suggest that blocking CD300f-ligand interactions not only contributes to an enhanced recruitment of macrophages but also to a change in the phenotype of normally recruited macrophages towards an early M2 phenotype, followed by a switch to a M1 phenotype of some macrophages later on. Interestingly, Mokarram and colleagues induced a nerve section followed by tubulization repair and IL-4 or INF $\gamma$ treatment to polarize macrophages towards a M2 or M1 phenotype, respectively. Only IL-4 but not INF $\gamma$ treatment induced increased Schwann cell migration, macrophage recruitment, macrophage polarization towards M2 phenotype, and regeneration [23]. In the absence of any treatment, they reported a main macrophage polarization towards an M1 phenotype at $21 \mathrm{dpl}$, while we show mainly a polarization towards an M2 phenotype at $28 \mathrm{dpl}$. Moreover, Mokarram and colleagues reported that the increase in CD206-positive cells at $21 \mathrm{dpl}$ positively correlated with regeneration, while we observe in fact a negative correlation at $10 \mathrm{dpl}$ and no correlation at 28 dpl. This apparent contradiction between both studies may be explained by the different nerve injury models, i.e., nerve crush versus section and tubulization, where the neuroinflammatory conditions are different and where the structural maintenance of the epi-, peri-, and endoneurium has strong effects. Moreover, the treatment with IL-4 may change fundamental endogenous neuroinflammatory mechanisms influencing the final outcome of regeneration observed.

\section{Conclusions}

Taken together, these results establish a role for CD300f in peripheral nerve injury, involving this immune receptor and its ligands in the regulation of neuroinflammation, M1/M2 macrophage recruitment and polarization, and nerve regeneration. Moreover, the ligands of CD300f most probably located in Schwann cells may constitute critical players that participate in Schwann cell-mediated interaction with macrophages. Further experiments are needed to better understand the mechanisms of action of CD300f in peripheral nerve neuroinflammation and regeneration and the putative role of other CD300f-expressing cells as mast cells or neutrophils. Moreover, additional work with other markers of M1/M2 phenotype has to be performed to unravel the phenotype of macrophages and their function after a peripheral nerve injury and how the absence of CD300f signaling might influence the pattern of inflammation. Finally, after a crush nerve injury, 
macrophages that take part in the first stage of WD $(1-10 \mathrm{dpl})$ would be polarized mainly towards a proinflammatory M1 phenotype whereas the resolution of inflammation at later stages $(15-30 \mathrm{dpl})$ would be driven predominantly by M2 macrophages.

\section{Competing interests}

The authors declare that they have no competing interests.

\section{Authors' contributions}

$\mathrm{NL}$ and HP conceived the study, designed and carried out most of the experiments, and wrote the manuscript. PS carried out the functional evaluation and part of the immunohistochemistry assays. MLN and JS produced and purified the CD300f-IgG2a fusion protein. NL, IFQ, and RLV performed the FACS analysis. XN, RLV, and JS contributed to the interpretation of the results and discussion. All the authors read and approved the final manuscript.

\section{Acknowledgements}

This research was supported by Fundació Marató TV3 (110533), Catalunya, Spain, Comisión Sectorial de Investigación Científica (CSIC-UDELAR), Uruguay, PEDECIBA, Uruguay, Agencia Nacional de Investigación e Innovación (ANII), Uruguay, and FOCEM (MERCOSUR Structural Convergence Fund), COF 03/ 1111, CIBERNED, and TERCEL funds from the Instituto de Salud Carlos III of Spain. The authors thank the technical help of Jessica Jaramillo, Marta Valeri, and Natalia Puig.

\section{Author details}

${ }^{1}$ Neuroinflammation and Gene Therapy Laboratory, Institut Pasteur Montevideo, Mataojo 2020, CP 11400 Montevideo, Uruguay. ${ }^{2}$ Department of Histology and Embryology, Faculty of Medicine, UDELAR, Montevideo, Uruguay. ${ }^{3}$ Institute of Neurosciences and Department of Cell Biology, Physiology and Immunology, Universitat Autònoma de Barcelona, and Centro de Investigación Biomédica en Red sobre Enfermedades Neurodegenerativas (CIBERNED), Bellaterra, Spain. ${ }^{4}$ Immunobiology Group, CIBBIM-Nanomedicine Program, Hospital Universitari Vall d'Hebron, Institut de Recerca (VHIR), Universitat Autonoma de Barcelona, Barcelona, Spain. ${ }^{5}$ Neurodegeneration Laboratory, Institut Pasteur Montevideo, Montevideo, Uruguay.

Received: 10 February 2015 Accepted: 21 July 2015

Published online: 12 August 2015

\section{References}

1. Lago N, Navarro X. Correlation between target reinnervation and distribution of motor axons in the injured rat sciatic nerve. J Neurotrauma. 2006;23:227-40.

2. Deumens R, Bozkurt A, Meek MF, Marcus MA, Joosten EA, Weis J, et al. Repairing injured peripheral nerves: bridging the gap. Prog Neurobiol. 2010;92:245-76.

3. Allodi I, Udina E, Navarro X. Specificity of peripheral nerve regeneration: interactions at the axon level. Prog Neurobiol. 2012;98:16-37.

4. Waller A. Experiments on the section of the glossopharyngeal and hypoglossal nerves of the frog, observations of the alterations produced thereby in the structure of their primitive fibers. Phil Transact Royal Soc London. 1850;140:423-9.

5. Vargas ME, Barres BA. Why is Wallerian degeneration in the CNS so slow? Annu Rev Neurosci. 2007;30:153-79.

6. Schafer M, Fruttiger M, Montag D, Schachner M, Martini R. Disruption of the gene for the myelin-associated glycoprotein improves axonal regrowth along myelin in C57BL/WIds mice. Neuron. 1996;16:1107-13.

7. Fruttiger M, Montag D, Schachner M, Martini R. Crucial role for the myelin-associated glycoprotein in the maintenance of axon-myelin integrity. Eur J Neurosci. 1995;7:511-5.

8. Gaudet AD, Popovich PG, Ramer MS. Wallerian degeneration: gaining perspective on inflammatory events after peripheral nerve injury. J Neuroinflammation. 2011;8:110.

9. Rotshenker S. Wallerian degeneration: the innate-immune response to traumatic nerve injury. J Neuroinflammation. 2011;8:109.
10. Avellino AM, Hart D, Dailey AT, Mackinnon M, Ellegala D, Kliot M. Differential macrophage responses in the peripheral and central nervous system during Wallerian degeneration of axons. Exp Neurol. 1995;136:183-98.

11. Omura T, Omura K, Sano M, Sawada T, Hasegawa T, Nagano A. Spatiotemporal quantification of recruit and resident macrophages after crush nerve injury utilizing immunohistochemistry. Brain Res. 2005;1057:29-36.

12. Be'eri H, Reichert F, Saada A, Rotshenker S. The cytokine network of Wallerian degeneration: IL-10 and GM-CSF. Eur J Neurosci. 1998;10:2707-13.

13. Shamash $S$, Reichert F, Rotshenker $S$. The cytokine network of Wallerian degeneration: tumor necrosis factor-alpha, interleukin-1alpha, and interleukin-1 beta. J Neurosci. 2002;22:3052-60.

14. Sawada T, Sano M, Omura T, Omura K, Hasegawa T, Funahashi S, et al. Spatiotemporal quantification of tumor necrosis factor-alpha and interleukin-10 after crush injury in rat sciatic nerve utilizing immunohistochemistry. Neurosci Lett. 2007;417:55-60.

15. Liefner M, Siebert $H$, Sachse T, Michel U, Kollias G, Bruck W. The role of TNF-alpha during Wallerian degeneration. J Neuroimmunol. 2000;108:147-52.

16. George A, Kleinschnitz C, Zelenka M, Brinkhoff J, Stoll G, Sommer C. Wallerian degeneration after crush or chronic constriction injury of rodent sciatic nerve is associated with a depletion of endoneurial interleukin-10 protein. Exp Neurol. 2004;188:187-91.

17. Gordon S. Alternative activation of macrophages. Nat Rev Immunol. 2003;3:23-35.

18. Geissmann F, Manz MG, Jung S, Sieweke MH, Merad M, Ley K. Development of monocytes, macrophages, and dendritic cells. Science. 2010;327:656-61.

19. Mantovani A, Sica A, Sozzani S, Allavena P, Vecchi A, Locati M. The chemokine system in diverse forms of macrophage activation and polarization. Trends Immunol. 2004;25:677-86.

20. David S, Kroner A. Repertoire of microglial and macrophage responses after spinal cord injury. Nat Rev Neurosci. 2011;12:388-99.

21. Kigerl KA, Gensel JC, Ankeny DP, Alexander JK, Donnelly DJ, Popovich PG. Identification of two distinct macrophage subsets with divergent effects causing either neurotoxicity or regeneration in the injured mouse spinal cord. J Neurosci. 2009;29:13435-44.

22. Ydens E, Cauwels A, Asselbergh B, Goethals S, Peeraer L, Lornet G, et al. Acute injury in the peripheral nervous system triggers an alternative macrophage response. J Neuroinflammation. 2012;9:176.

23. Mokarram N, Merchant A, Mukhatyar V, Patel G, Bellamkonda RV. Effect of modulating macrophage phenotype on peripheral nerve repair. Biomaterials. 2012;33:8793-801.

24. Hoek RM, Ruuls SR, Murphy CA, Wright GJ, Goddard R, Zurawski SM, et al. Down-regulation of the macrophage lineage through interaction with OX2 (CD200). Science. 2000;290:1768-71.

25. Neumann H, Takahashi K. Essential role of the microglial triggering receptor expressed on myeloid cells-2 (TREM2) for central nervous tissue immune homeostasis. J Neuroimmunol. 2007;184:92-9.

26. Alvarez-Errico D, Aguilar H, Kitzig F, Brckalo T, Sayos J, Lopez-Botet M. IREM-1 is a novel inhibitory receptor expressed by myeloid cells. Eur J Immunol. 2004;34:3690-701.

27. Aguilar H, Alvarez-Errico D, Garcia-Montero AC, Orfao A, Sayos J, LopezBotet M. Molecular characterization of a novel immune receptor restricted to the monocytic lineage. J Immunol. 2004;173:6703-11.

28. Alvarez-Errico D, Sayos J, Lopez-Botet M. The IREM-1 (CD300f) inhibitory receptor associates with the p85alpha subunit of phosphoinositide 3-kinase. J Immunol. 2007;178:808-16.

29. Comas-Casellas E, Martinez-Barriocanal A, Miro F, Ejarque-Ortiz A, Schwartz Jr S, Martin M, et al. Cloning and characterization of CD300d, a novel member of the human CD300 family of immune receptors. J Biol Chem. 2012;287:9682-93.

30. Martinez-Barriocanal A, Sayos J. Molecular and functional characterization of CD300b, a new activating immunoglobulin receptor able to transduce signals through two different pathways. J Immunol. 2006;177:2819-30.

31. Borrego F. The CD300 molecules: an emerging family of regulators of the immune system. Blood. 2013;121(11):1951-60.

32. Martinez-Barriocanal A, Comas-Casellas E, Schwartz Jr S, Martin M, Sayos J. CD300 heterocomplexes, a new and family-restricted mechanism for myeloid cell signaling regulation. J Biol Chem. 2010;285:41781-94.

33. Torres-Espin A, Hernandez J, Navarro X. Gene expression changes in the injured spinal cord following transplantation of mesenchymal stem cells or olfactory ensheathing cells. PLoS ONE. 2013;8, e76141. 
34. Nielsen R, Bustamante C, Clark AG, Glanowski S, Sackton TB, Hubisz MJ, et al. A scan for positively selected genes in the genomes of humans and chimpanzees. PLoS Biol. 2005;3, e170.

35. Choi SC, Simhadri VR, Tian L, Gil-Krzewska A, Krzewski K, Borrego F, et al. Cutting edge: mouse CD300f (CMRF-35-like molecule-1) recognizes outer membrane-exposed phosphatidylserine and can promote phagocytosis. J Immunol. 2011;187:3483-7.

36. Tian L, Choi SC, Murakami Y, Allen J, Morse 3rd HC, Qi CF, et al. p85alpha recruitment by the CD300f phosphatidylserine receptor mediates apoptotic cell clearance required for autoimmunity suppression. Nat Commun. 2014;5:3146

37. Ejarque-Ortiz A, Sola C, Martinez-Barriocanal A, Schwartz Jr S, Martin M, Peluffo $\mathrm{H}$, et al. The receptor CMRF35-like molecule-1 (CLM-1) enhances the production of LPS-induced pro-inflammatory mediators during microglial activation. PLoS ONE. 2015;10, e0123928.

38. Moshkovits I, Karo-Atar D, Itan M, Reichman H, Rozenberg P, MorgensternBen-Baruch N, et al. CD300f associates with IL-4 receptor a and amplifies IL-4-induced immune cell responses. Proc Natl Acad Sci U S A. 2015;112(28):8708-13.

39. Xi H, Katschke Jr KJ, Helmy KY, Wark PA, Kljavin N, Clark H, et al. Negative regulation of autoimmune demyelination by the inhibitory receptor CLM-1. J Exp Med. 2010;207:7-16.

40. Izawa K, Yamanishi Y, Maehara A, Takahashi M, Isobe M, Ito S, et al. The receptor LMIR3 negatively regulates mast cell activation and allergic responses by binding to extracellular ceramide. Immunity. 2012;37:827-39.

41. Cannon JP, O'Driscoll M, Litman GW. Specific lipid recognition is a general feature of CD300 and TREM molecules. Immunogenetics. 2012;64:39-47.

42. Izawa K, Isobe M, Matsukawa T, Ito S, Maehara A, Takahashi M, et al. Sphingomyelin and ceramide are physiological ligands for human LMIR3/ CD300f, inhibiting FcepsilonRI-mediated mast cell activation. J Allergy Clin Immunol. 2014;133:270-3. e271-277

43. Feng G, Mellor RH, Bernstein M, Keller-Peck C, Nguyen QT, Wallace M, et al. Imaging neuronal subsets in transgenic mice expressing multiple spectral variants of GFP. Neuron. 2000;28:41-51.

44. Ale A, Bruna J, Morell $M$, van de Velde $H$, Monbaliu J, Navarro X, et al. Treatment with anti-TNF alpha protects against the neuropathy induced by the proteasome inhibitor bortezomib in a mouse model. Exp Neurol. 2014:253:165-73

45. Klopstein A, Santos-Nogueira E, Francos-Quijorna I, Redensek A, David S, Navarro X, Lopez-Vales R: Beneficial effects of alphaB-crystallin in spinal cord contusion injury. J Neurosci 2012, 32:14478-14488.

46. Fricker FR, Lago N, Balarajah S, Tsantoulas C, Tanna S, Zhu N, et al. Axonally derived neuregulin-1 is required for remyelination and regeneration after nerve injury in adulthood. J Neurosci. 2011;31:3225-33.

47. Bain JR, Mackinnon SE, Hunter DA. Functional evaluation of complete sciatic, peroneal, and posterior tibial nerve lesions in the rat. Plast Reconstr Surg. 1989;83:129-38.

48. Lopez-Vales R, Navarro X, Shimizu T, Baskakis C, Kokotos G, Constantinou-

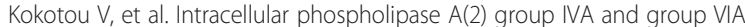
play important roles in Wallerian degeneration and axon regeneration after peripheral nerve injury. Brain. 2008;131:2620-31.

49. Pfaffl MW. A new mathematical model for relative quantification in real-time RT-PCR. Nucleic Acids Res. 2001;29, e45.

50. Peluffo H, Ali-Ruiz D, Ejarque-Ortiz A, Heras-Alvarez V, Comas-Casellas E, Martinez-Barriocanal A, et al. Overexpression of the immunoreceptor CD300f has a neuroprotective role in a model of acute brain injury. Brain Pathol. 2011:22:318-28.

51. Fricker FR, Zhu N, Tsantoulas C, Abrahamsen B, Nassar MA, Thakur M, et al. Sensory axon-derived neuregulin-1 is required for axoglial signaling and normal sensory function but not for long-term axon maintenance. J Neurosci. 2009;29:7667-78.

52. Groves ML, McKeon R, Werner E, Nagarsheth M, Meador W, English AW. Axon regeneration in peripheral nerves is enhanced by proteoglycan degradation. Exp Neurol. 2005;195:278-92.

53. Beirowski B, Berek L, Adalbert R, Wagner D, Grumme DS, Addicks K, et al. Quantitative and qualitative analysis of Wallerian degeneration using restricted axonal labelling in YFP-H mice. J Neurosci Methods. 2004;134:23-35.

54. English AW, Meador W, Carrasco DI. Neurotrophin-4/5 is required for the early growth of regenerating axons in peripheral nerves. Eur J Neurosci. 2005;21:2624-34
55. Acarin L, Vela JM, Gonzalez B, Castellano B. Demonstration of poly-N-acetyl lactosamine residues in ameboid and ramified microglial cells in rat brain by tomato lectin binding. J Histochem Cytochem. 1994;42:1033-41.

56. Peluffo H, Acarin L, Faiz M, Castellano B, Gonzalez B. Cu/Zn superoxide dismutase expression in the postnatal rat brain following an excitotoxic injury. J Neuroinflammation. 2005;2:12.

57. Phongsisay V, lizasa E, Hara H, Yamasaki S. 3-O-sulfo-beta-d-galactose moiety of endogenous sulfoglycolipids is a potential ligand for immunoglobulin-like receptor LMIR5. Mol Immunol. 2015;63:595-9.

58. Court FA, Zambroni D, Pavoni E, Colombelli C, Baragli C, Figlia G, et al. MMP2-9 cleavage of dystroglycan alters the size and molecular composition of Schwann cell domains. J Neurosci. 2011;31:12208-17.

59. Chang $\mathrm{CY}$, Lee $\mathrm{YH}$, Jiang-Shieh YF, Chien HF, Pai MH, Chen HM, et al. Novel distribution of cluster of differentiation 200 adhesion molecule in glial cells of the peripheral nervous system of rats and its modulation after nerve injury. Neuroscience. 2011;183:32-46.

60. Linnartz B, Wang Y, Neumann H. Microglial immunoreceptor tyrosinebased activation and inhibition motif signaling in neuroinflammation. Int J Alzheimers Dis. 2010;2010.

61. Biber K, Neumann H, Inoue K, Boddeke HW. Neuronal 'On' and 'Off' signals control microglia. Trends Neurosci. 2007;30:596-602.

62. Ransohoff RM, Cardona AE. The myeloid cells of the central nervous system parenchyma. Nature. 2010;468:253-62.

63. Kim EJ, Lee SM, Suk K, Lee WH. CD300a and CD300f differentially regulate the MyD88 and TRIF-mediated TLR signalling pathways through activation of SHP-1 and/or SHP-2 in human monocytic cell lines. Immunology. 2012;135:226-35

64. Mueller M, Leonhard C, Wacker K, Ringelstein EB, Okabe M, Hickey WF, et al. Macrophage response to peripheral nerve injury: the quantitative contribution of resident and hematogenous macrophages. Lab Invest. 2003:83:175-85

65. Nadeau S, Filali M, Zhang J, Kerr BJ, Rivest S, Soulet D, et al. Functional recovery after peripheral nerve injury is dependent on the pro-inflammatory cytokines IL-1 beta and TNF: implications for neuropathic pain. J Neurosci. 2011:31:12533-42.

\section{Submit your next manuscript to BioMed Central and take full advantage of:}

- Convenient online submission

- Thorough peer review

- No space constraints or color figure charges

- Immediate publication on acceptance

- Inclusion in PubMed, CAS, Scopus and Google Scholar

- Research which is freely available for redistribution 